\title{
Superplastic Behavior of Alumina Composites Mediated by Carbon Nanotubes
}

\author{
Xiaobing Zhou ${ }^{1}$, Lei Li ${ }^{1}$, Lu Shen ${ }^{1}$, Jie Zhou ${ }^{1}$, Junwei Zhang ${ }^{1}$, Amiya K. Mukherjee ${ }^{2}$, Changshu Xiang ${ }^{3}$, \\ Huiping Tang ${ }^{3}$, Qing Huang ${ }^{1, *}$
}

(Received 8 June 2013; accepted 9 July 2013; published online 25 July 2013)

\begin{abstract}
The high temperature creep behavior of carbon nanotube (CNT)/alumina was mediated by the surface chemical functionalization used for synthesis of composite powders. Non-covalent functionalized carbon nanotubes make composites ductile, but covalent approach leads composites that are creep-resistant. Oxygen vacancy mechanism is proposed to account for this mediation effect in this communication.
\end{abstract}

Keywords: Carbon nanotubes; Alumina; Microstructure; Superplasticity

Citation: Xiaobing Zhou, Lei Li, Lu Shen, Jie Zhou, Junwei Zhang, Amiya K. Mukherjee, Changshu Xiang, Huiping Tang and Qing Huang, "Superplastic Behavior of Alumina Composites Mediated by Carbon Nanotubes", Nano-Micro Lett. 5(3), 174-181 (2013). http://dx.doi.org/10.5101/nml.v5i3.p174-181

\section{Introduction}

Superplasticity relates the ability of polycrystalline solids to demonstrate extremely large elongation during stretching at elevated temperatures that are much lower than the melting point of the crystal [1]. It is wellknown that lattice dislocation slip that is the dominant mechanism of plastic behavior in metals is suppressed in ceramics. High Peierls barrier for lattice dislocation slip in ceramics often account for their brittle character [2]. However, previous works on nanocrystalline or ultra-fine micro-crystalline ceramics show extraordinary elongation up to $1000 \%$, indicating that the potential application of plastically forging process in industry could be realized in ceramics [3].

Two dynamic and concurrent processes are proposed during plastic flow of ceramic grains: cavity formation and process to accommodate grain boundary sliding. Grain boundary sliding produces fresh surface absorbing mechanical energy. Stable interfaces merge at triple points and form cavities if dislocation motion or volume and surface diffusion of atoms can not accommodate them [4]. Therefore, superfine grain of ceramics limited dynamic grain growth during forging is regarded the optimum condition to achieve the superplasticity, and has been reflected in the phenomenal creep equation developed by Mukherjee et al. [5]. Small grain size realizes the short dislocation motion distance and the matter transportation distance across the surface or through volume, thus benefits the accommodation process.

Besides by controlling the grain size, superplastic flow behavior of ceramics at low temperature can also achieved by engineering their grain boundary. For the solid-state-sintering (SSS) ceramics whose grain boundaries have no liquid phase, their diffusion creep rate largely relates to the density and type of vacancy near the surface of grain. Dislocation will move along grain boundary to annihilate and generate vacancies. This interface-reaction-controlled creep becomes dominant when the creation/annihilation rate of vacancy or attachment/detachment of atoms is lower than diffusional transport rate [6]. However, the effective approach to engineer the grain boundary of SSS ceramics is needed

\footnotetext{
${ }^{1}$ Division of Functional Materials and Nanodevices, Ningbo Institute of Materials Technology and Engineering (NIMTE), Chinese Academy of Sciences (CAS), Ningbo, Zhejiang 315201, China

${ }^{2}$ Department of Chemical Engineering \& Materials Science, University of California, Davis, CA 95616, USA

${ }^{3}$ State Key Laboratory of Porous Metal Materials, Northwest Institute for Nonferrous Metal Research, Xi'an 710016, China

*Corresponding author. E-mail: huangqing@nimte.ac.cn
} 
to be developed.

Recently, Huang et al. reported that addition of small amount of BN nanotubes (BNNTs) (0.5 wt\%) into alumina and silicon nitride ceramics made them more ductile at moderate temperatures than corresponding pristine ceramics [7]. The static grain growth in the as-sintered BNNT/alumina and the following dynamic grain growth after compressive deformation are dramatically inhibited. For example, in the respective $0.5 \mathrm{wt} \% \mathrm{BNNT} /$ ceramic composites, un-deformable alumina ceramic shows promising superplastic behavior even at as low as $1300^{\circ} \mathrm{C}$ without crack formation; Nanocrystalline silicon nitride ceramic deforms plastically much easily and exhibits a true stress as low as $20 \mathrm{MPa}$. The stress concentration near triple-point boundary was efficiently relaxed by deformable BNNTs locating on the grain boundary, which was proposed as the reason of slow grain growth. Also, dissolutionprecipitation process on the fresh interfaces must be blocked by BNNTs, which leads to inevitable cavitation phenomenon.

In the nanocrystalline ceramics, cavitation effect will be balanced by the sliding of ultrafine grains that fill the cavities that are formed as shown in superplastic silicon nitride ceramics when average diameter of BNNTs is comparable to grain size. Interestingly, Zapata-solvas et al. [8] reported the 10 vol\% single walled carbon nanotube (SWCNT) /alumina ceramics are about two orders of magnitude more creep-resistant when compared to a pure alumina ( $0.5 \mu \mathrm{m}$ in grain size), and attributed this seemingly conflicting result to partial blocking of grain-boundary sliding by SWCNTs. Authors proposed that the tension existed in the SWCNTs alignment on the grain boundary must impede the sliding process, thus a high stress is needed to realize the dislocation slip. However, Bataille et al. [9] have given solid evidence that the presence of $1.3 \mathrm{wt} \%$ of carbon in the alumina greatly reduces the grain growth both in assintered and deformed ceramics. The initial flow stress in the carbon-doped alumina is about half of that without doping under the strain rate of $10^{-4} / \mathrm{s}$ at temperature of $1400^{\circ} \mathrm{C}$. This enhanced plastic flow behavior of alumina by adding graphite particles is similar to results unraveled in BNNT/alumina composites. The conflict investigation conduced by Zapata-solvas et al. may due to the grain size of alumina and the original source of carbon nanotubes which control the intrinsic creep behavior of composites. Also, the content and distribution of CNTs in the as-sintered alumina ceramics impact the grain boundary sliding mechanism during deformation.

In this communication, we report that the creep behavior of alumina can be mediated by CNTs through different surface functionalization approach that is used in the initial synthesis of composite powders. Noncovalent functionalization-dispersed CNTs made the alumina ceramics more deformable, but acid-treated CNTs, on the contrary, enhanced the creep-resistance ability of the matrix. A tentative oxygen-vacancydefect controlled mechanism was proposed in the final discussion.

\section{Experimental}

\section{Powder preparation}

For non-covalent functionalization samples, CNTs (Nanostructured \& Amorphous Materials Inc.) and cellulose sodium lignosulfonate (SLS, Aldrich) were mixed in de-ionized water and sonicated in an ultrasonic processor (Cole-Parmer) for $45 \mathrm{~min}$, followed by sonication in ultrasonic bath for $1 \mathrm{~h}$. Alumina nanoparticles (150 nm, Taimei Chemical Co., Japan) were first dispersed in de-ionized water with $\mathrm{pH}$ adjusted to a value of 3 through sonication process in ultrasonic bath. The CNTs solution was added dropwise into the alumina solution under vigorous stirring to form a stable CNT/alumina sol solution. Finally, poly(ethylenenimine) (PEI, Mw $\sim 750,000$, Aldrich) solution was used to cross-link as-prepared composite sol solution, and agglomerated composite particles soon settled down to the bottom of the beaker leaving clear supernatant that is easy to be filtered. The composite particles were rinsed in de-ionized water, and then in ethanol before the electrospinning process. For covalent functionalization samples, CNTs were refluxed in concentrated $\mathrm{HNO}_{3}$ solution at $180^{\circ} \mathrm{C}$ for $8 \mathrm{~h}$. Then, CNTs mixed with alumina powders following the same procedures described above.

High energy ball milling treatment was performed in a WC vial set fixed in a mixer (8000 series mixer, SPEX, USA). The weight ratio of WC ball and powder is 2:1.1 wt\% polyvinylalcohol (PVA) was used in case of particle agglomeration during ball milling.

\section{Sintering of ceramics}

In this study, consolidation of ceramics was performed with a Sumitomo SPSS-825S furnace. Small ceramic cylinders with the diameter of $9 \mathrm{~mm}$ and height of $6.5 \mathrm{~mm}$ were first sintered at temperature of $1200^{\circ} \mathrm{C}$ for $5 \mathrm{~min}$. A pressure of $65 \mathrm{MPa}$ was applied when temperature reached $600^{\circ} \mathrm{C}$ as measured by pyrometer through a side hole in the center of graphite die.

\section{In-situ forging}

The forging operation was also performed in the spark plasma sintering (SPS) furnace. A bigger graphite die with diameter of $19 \mathrm{~mm}$ was used to provide enough space for radial expansion during compressive deformation. In detail, small ceramic cylinder was put between plungers and was near center of big graphite die. Pre- 
pressure of $10 \mathrm{MPa}$ was applied to the samples in the beginning and switched to $65 \mathrm{MPa}$ when temperature reached $800^{\circ} \mathrm{C}$. The load was kept constant until the target temperature had been held for $2 \mathrm{~min}$. Force and displacement as the function of time were recorded in the SPS computer system.

\section{Characterization}

The morphologies of fracture surfaces of ceramics were examined by a scanning electron microscopy (SEM) (XL 30-SFEG, FEI/Philips, USA). The phase and anisotropic grain alignment were identified in Xray diffraction spectrometer (Scintag XDS 2000 powder diffractometer). The thermoluminescence (TL) measurements were performed on Ris $\emptyset$ TL/OSL-DA-15 automatic reader (Ris $\emptyset$ National Laboratory, Denmark) with an integrated ${ }^{90} \mathrm{Sr} /{ }^{90} \mathrm{Y}$ beta source.

\section{Results and discussion}

The sintering and forging setups are shown in Fig. 1(a) and 1(b), respectively. Figure 1(c) illustrates real objects of as-sintered and deformed $1 \mathrm{wt} \%$ noncovalent functionalized carbon nanotube/alumina (NC$\mathrm{CNT}$ /alumina) ceramics. It is worth noting that no crack was found in the rim of forged ceramic, demonstrating the excellent ductility. The CNT/alumina composite powders were synthesized according to our previously reported methodology in that CNTs were non-covalent functionalized (NC-CNTs) [10]. Covalentfunctionalization of CNTs (C-CNTs) was performed according to the commonly accepted method in which CNTs were refluxed in the boiled $\mathrm{HNO}_{3}$ solution at $180^{\circ} \mathrm{C}$ for $8 \mathrm{~h}$. C-CNT/alumina composite powders

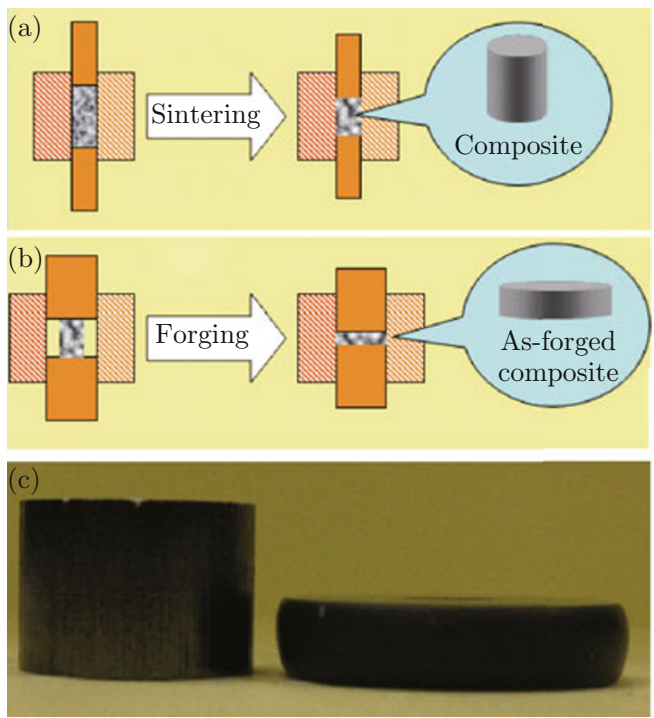

Fig. 1 Graphite die setup for small ceramic cylinder sintering (a) and subsequent forging (b). Real objects of assintered (left) and deformed samples (right). were synthesized following the same steps as the procedure for NC-CNT/alumina composite powders. All products obtained have high relative density over $99 \%$.

High-energy-ball-milling (HEBM) technique is an efficient way to activate the surface atoms of ceramic particles and to enhance their sintering ability [11]. Meanwhile, the $1.5 \mathrm{wt} \% \mathrm{NC}-\mathrm{CNT} /$ alumina ceramic starting from HEBM-treated alumina powder presents a better plastic flow behavior when compared to ceramic using as-received alumina powders as shown in Fig. 2(a). The displacement rates of ceramics originated for HEBM and as-received powders are $0.08 \mathrm{~mm} / \mathrm{s}$ and $0.02 \mathrm{~mm} / \mathrm{s}$ in the temperature range from $1250^{\circ} \mathrm{C}$ to $1400^{\circ} \mathrm{C}$, respectively. Surface activation by HEBM technique benefits the matter transport along the grain boundary since more bulk and surface defects are generated. The stored strain energy in the distorted particles may provide an additional driving force for both consolidation process and grain boundary sliding, favoring the sintering ability and flow capability at high temperature as observed in Fig. 2(a). More interestingly, surface functionalization of CNTs in the initial composite powder preparation played a decisive role in the final creep behavior of ceramics. HEBM treated alumina powders were used in the following composites as described below. In $2 \mathrm{wt} \%$ alumina composites, NC-CNT one illustrates an obvious superplasticity behavior, but C-CNT sample shows a remarkable creep-resistance property (Fig. 2(b)). No macroscopic edge cracking was observed in either of these two as-forged samples. NC-CNTs are attached by lignosulfonate molecules composing of phenylpropane group through $\pi-\pi$ interaction [10]. On the contrary, the sidewalls of C-CNTs are highly destroyed in the acid solution, and the density of oxygen atoms deriving from hydroxyl and carboxyl groups grafted on the sidewall and on the tip is much higher than that on NC-CNTs. In other words, C-CNTs can be regarded as oxidized CNTs.

To understand whether the oxygen interfere with the deformation process, the C-CNT/alumina powders were thermally treated in nitrogen environment at $600^{\circ} \mathrm{C}$ and $900^{\circ} \mathrm{C}$ before sintering in SPS furnace. Although the exact temperatures at which the hydroxyl and carboxyl groups are reduced were not fully investigated, scientists have used annealing process in inert atmospheres to eliminate the oxygen atoms on the surfaces of CNTs and carbon fibers. Toebes et al. [12] found that surface oxygen density of 2.8 atoms $/ \mathrm{nm}^{2}$ in oxidized carbon fibers will be decreased to 0.06 atoms $/ \mathrm{nm}^{2}$ through annealing at $700^{\circ} \mathrm{C}$ in $\mathrm{N}_{2}$ atmosphere. Consequently, the $2 \mathrm{wt} \% \mathrm{C}-\mathrm{CNT} /$ alumina composites gradually transformed their creep-resistance behavior back to plastic behavior as NC-CNT/alumina does (Fig. 2(c)). The sample undergone annealing at $990^{\circ} \mathrm{C}$ achieved a final compressive strain (calculated from the displacement record) of 0.53 that is a little 

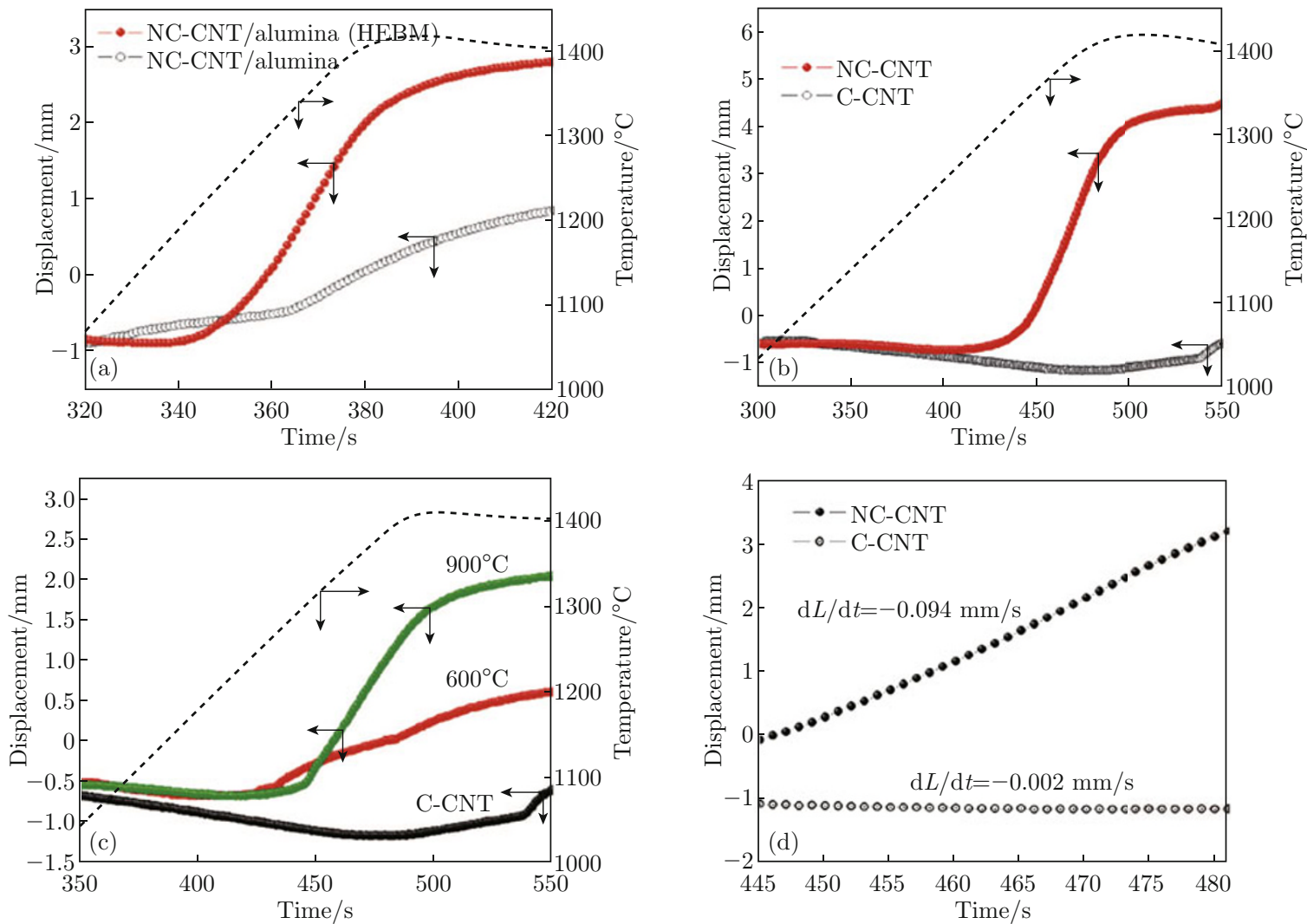

Fig. 2 (a) Time dependence of displacement and temperature recorded during forging in 1.5 wt\% NC-CNT-doped alumina materials using HEBM treated and as-received alumina powders. (b) Time dependence of displacement and temperature recorded during forging in $2 \mathrm{wt} \%$ alumina (HEBM) materials doped by non-covalent and covalent functionalized CNTs. (c) Creep behavior transition in 2 wt\% alumina (HEBM) materials doped by C-CNTs through high temperature annealing approach. (d) Partial time dependence of displacement of $2 \mathrm{wt} \%$ alumina (HEBM) materials doped by non-covalent and covalent functionalized CNTs in the temperature ranging from $1300^{\circ} \mathrm{C}$ to $1400^{\circ} \mathrm{C}$.

lower than the observed value of 0.66 in 2 wt\% NCCNT/alumina counterpart (Fig. 2(b)). This discrepancy is likely due to the de-activation of HEBM-treated alumina powders during thermally annealing at high temperature. The displacement rates of NC-CNT and C-CNT composites were calculated to be $0.094 \mathrm{~mm} / \mathrm{s}$ and $-0.002 \mathrm{~mm} / \mathrm{s}$ (Fig. 2(d)). The negative displacement rate in C-CNT/alumina sample can be attributed to its thermal expansion.

The two distinct creep behaviors in alumina ceramics doped by two different CNTs emphasize the important role of surface chemistry of CNTs on the final mechanical properties of composites. CNTs have a large specific surface area, and thus their surface functional groups become notable in controlling the surface defect chemistry of grain boundary in ceramics. CNTs have no tendency to react with alumina under atmospheric pressure even at temperature of $1600^{\circ} \mathrm{C}$ according to theoretical prediction by Gibbs reaction free energy. However, under some extreme conditions, carbon atoms will diffuse into alumina lattices or form new phases through interaction with defects. In particular, our previous study demonstrated that the pulsed cur- rent in SPS furnace destabilized the structures of CNTs and carbon atoms seemingly enter into alumina lattices as analyzed by Raman technique [13]. According to defect chemistry, carbon atoms on the surface of CNTs have a high possibility of displacing the lattice position of aluminum or oxygen on the surface of neighboring alumina grain. Two doping mechanisms have been proposed in a previous report; either of them will lead to the formation of oxygen vacancy defect [14]. One supposes a positive bivalent carbon substitutes a positive trivalent aluminum atom, and a half an oxygen vacancy will form in order to preserve the electrical neutrality (Eq. (1)). Another possible mechanism is that a negative quadrivalent carbon atom takes place of a negative bivalent oxygen atom and another oxygen atom had to leave to provide room for doped carbon atom (Eq. (2)).

$$
\begin{aligned}
& \left.C+\mathrm{Al}_{2} \mathrm{O}_{3(\text { lattice })} \rightarrow\left(C_{A l^{+3}}^{+2}\right)^{-}+1 / 2 V_{O}^{\bullet \bullet} \quad \text { (F center }\right) \\
& C+\mathrm{Al}_{2} \mathrm{O}_{3(\text { lattice })} \rightarrow\left(C_{\mathrm{O}^{-2}}^{-4}\right)^{2-}+V_{O}^{\bullet \bullet}
\end{aligned}
$$

The defects such as $\left(C_{A l^{+3}}^{+2}\right)^{-}$and $V_{O}^{\bullet \bullet}$, or their defect complexes may enhance the deformation process. This 
charge-compensation doping effect has been discussed by Xue et al. [15] in the zirconia system. NC-CNTs can be a carbon source at the high temperature and under vacuum condition $(5 \mathrm{~Pa})$, and promote the $V_{O}^{\bullet \bullet}$ generation during deformation. However, C-CNTs are coated by O-containing functional groups, and these oxygen atoms annihilate the oxygen vacancies or even prohibit their formation (Eq. (3) and Eq. (4)).

$$
\begin{aligned}
& V_{O}^{\bullet \bullet}+-C_{C N T}-O H \rightarrow \\
& \quad-C_{C N T}+O_{\text {lattice }}+1 / 2 H_{2} \\
& 2 V_{O}^{\bullet \bullet}+-(H O) C_{C N T}=O \rightarrow \\
& \quad-C_{C N T}+2 O_{\text {lattice }}+1 / 2 H_{2}
\end{aligned}
$$

Oxygen vacancies in alumina grains can be quantitatively detected by thermoluminescence (TL) technique since this defect has capability to trap the highenergy electron irradiated by calibrated ${ }^{90} \mathrm{Sr} /{ }^{90} \mathrm{Y}$ beta source [16]. This excited electron trapped by oxygen vacancy ( $F$ color center) will go back to the lowenergy-state at a characteristic temperature, and release the energy in the form of photoluminescence that can be detected. Through this optical approach, we will explore the relationship between the creep behavior and the chemical defect on the grain boundary. In fact, these CNT/alumina samples present different intensity of thermoluminescence. NC-CNT/alumina ceramic emits TL more strongly than $\mathrm{C}-\mathrm{CNT} /$ alumina does (Fig. 3). The shift of characteristic TL peaks in NC-CNT/alumina ceramic to high temperatures means that the oxygen vacancy may form defect complexes with other forms of defects (such as $\left(C_{A l^{+3}}^{+2}\right)^{-}$) that are more thermodynamically stable than isolated ones. Obviously, HEBM-treated alumina provides enormous activated surface atoms and defects that increase the possibility of formation these dopant-defect complexes. The above tentatively proposed oxygen vacancy model may explains the conflicting results in the carbon-doped

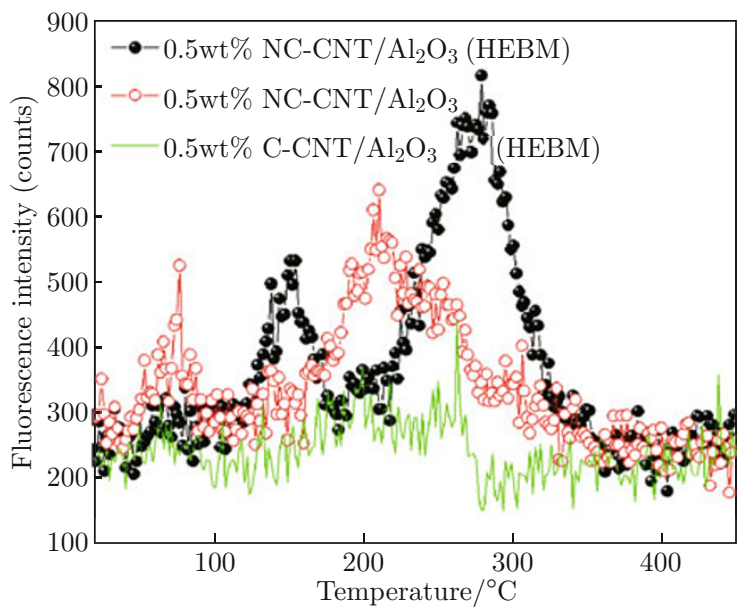

Fig. 3 Thermoluminescence of $\mathrm{CNT} /$ alumina samples showing their oxygen vacancy concentrations. alumina and SWCNT/alumina, Zapata-Solvus et al. used a highly-oxidized CNTs in their powder preparation [8], but Bataille et al. introduced carbon particles by graphitization of polymer in the vacuum condition [9]. The later graphite material contains much less oxygen atoms than acid-oxidized CNTs. These results again address the importance of surface chemical functionalization of CNTs in mediating the resultant mechanical properties of composites even at high temperature.

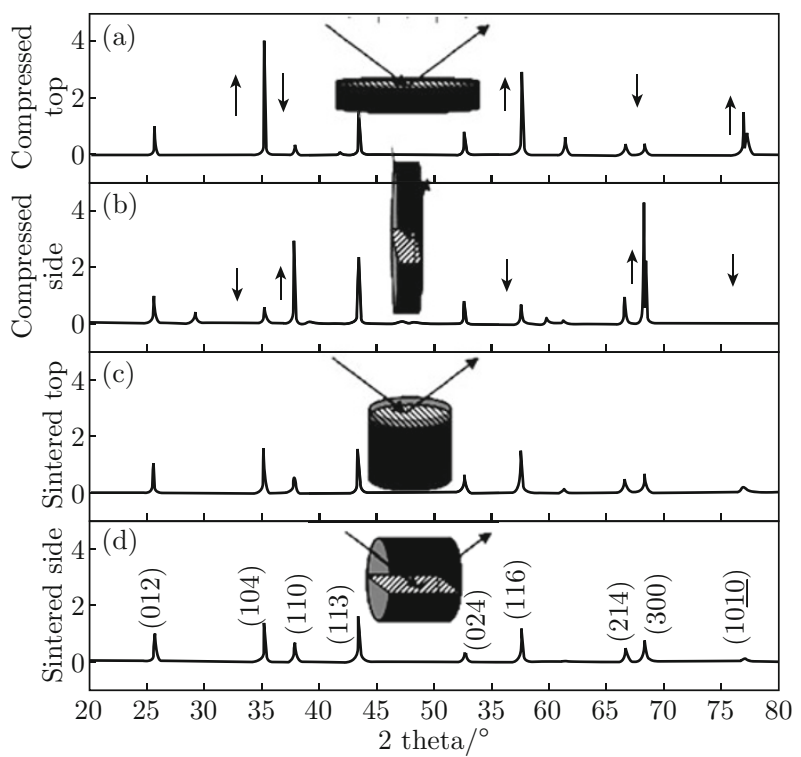

Fig. 4 XRD patterns of as-forged 2 wt $\%$ NC-CNT/alumina ceramic taken on the top surface (a) and on the side surface (b). (c) and (d) XRD patterns of as-sintered ceramics. All spectra are normalized at the (012) peak for easy comparison.

Interestingly, the as-forged NC-CNT/alumina demonstrates an anisotropic character in the X-ray diffraction (XRD) patterns. The intensities of prismatic crystallographical planes or plans having low interplanar angles to prismatic planes, such as (1014), (0006), (11 $\overline{2} 6),(10 \overline{1} 0)$, are largely enhanced in the top surface of as-forged $2 \mathrm{wt} \% \mathrm{NC}-\mathrm{CNT} /$ alumina. Instead, the intensities of base plane or planes having high interplanar angles to prismatic planes, such as $(11 \overline{2} 0),(11 \overline{2} 3),(30 \overline{3} 0)$, are enhanced. The spectra of as-sintered $2 \mathrm{wt} \% \mathrm{NC}-\mathrm{CNT} /$ alumina taken on the top surface and side surface are also investigated. No visible difference is observed in them, indicating that the anisotropy feature in the as-forged sample is not due to the field effect during SPS sintering.

The textured microstructures of as-forged samples can be further identified in their fracture surface (Fig. 5(a) and 5(b)). Platelet-like grains align together and are parallel to the compressed surface. It is hard to observe the CNTs in the $2 \mathrm{wt} \% \mathrm{NC}-\mathrm{CNT} /$ alumina ceramics due to the high density of pulsed current during SPS sintering, which has been discussed in our previous 

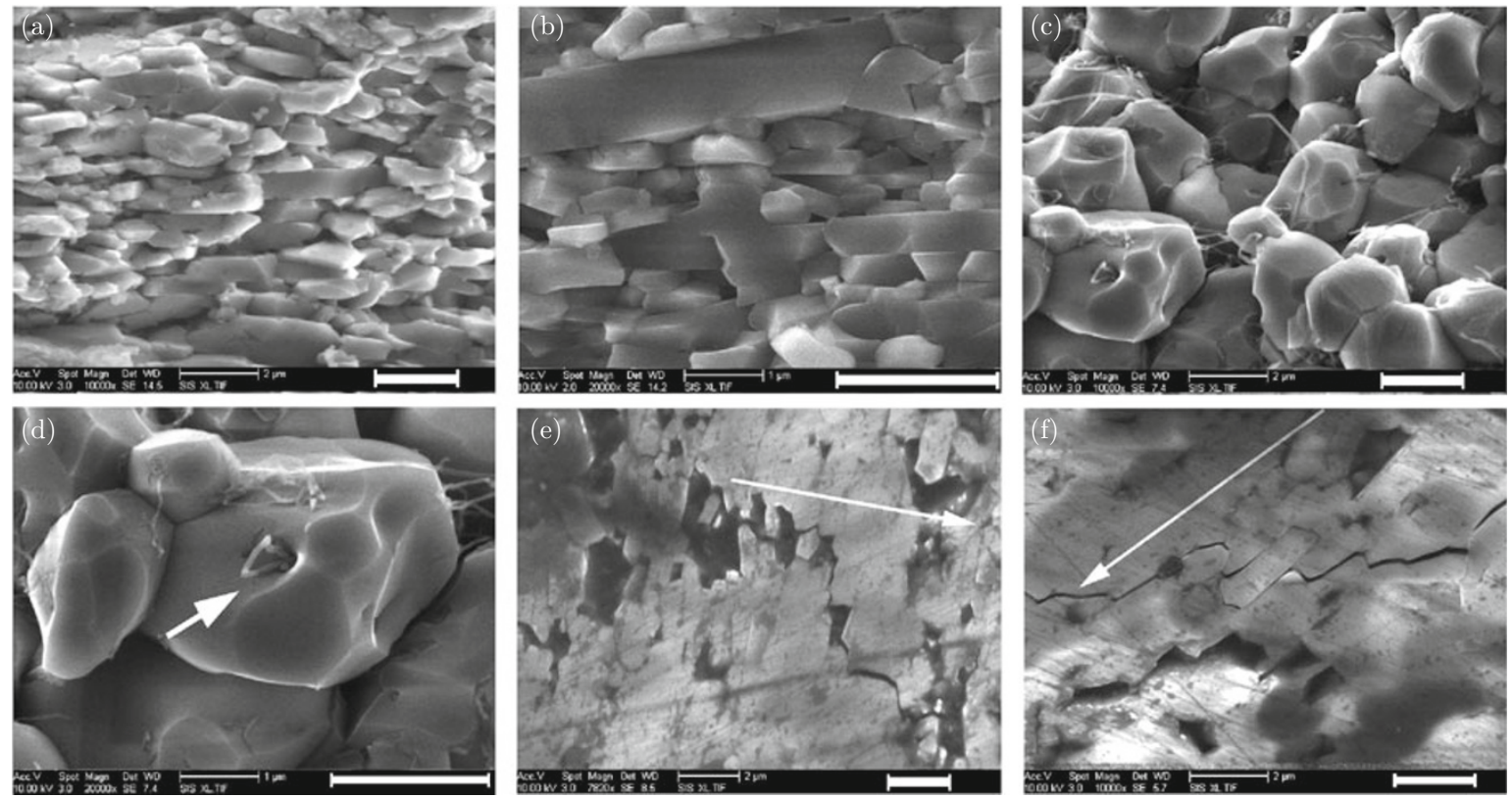

Fig. 5 SEM images showing fracture surfaces of as-forged NC-CNT/alumina (a) and (b), and of C-CNT/alumina ceramics (c) and $(\mathrm{d})$. Crack propagation mode in as-forged NC-CNT/alumina, the maximum indentation stress should be perpendicular to (e) or parallel to (f) prismatic plane of platelet grains. White arrows indicate the direction of maximum indentation stress. The bars are $2 \mu \mathrm{m}$.

report [13]. Moreover, no visible void can be noticed in between the grain boundary that is consistent with fact that as-forged products are still fully dense. The 'brick-wall' structure of alumina grains is consistent to the XRD results. The platelet grains lay down and stack up with their prismatic surfaces perpendicular to load applied during forging. On the contrary, most of CNTs are finally preserved both in as-sintered and asforged $2 \mathrm{wt} \% \mathrm{C}$-CNT/alumina ceramics (Fig. 5(c)). It seems the compatibility between CNTs and alumina grains is poor (see arrowed CNT in Fig. 5(d)). CNTs are pulled out from grain boundary after deformation, indicating the weak interface bonding between them. The alumina grains also became coarse after forging and plenty of voids formed. It can be reasonably proposed that oxygen atoms on the surface of oxidized CNTs diminished or retarded the formation of oxygen vacancy defect, which may lead to the lowering of the diffusional transportation of aluminum atoms. Also, surface oxidization of CNTs increases their electrical resistivity, which reduces the detrimental pulsed current density during SPS operation and explains the resultant structural stability of CNTs. The textured structure in as-forged NC-CNT/alumina ceramics can be a very promising method to improve the fracture toughness through mechanism of crack deflection. Actually, the crack propagation was impeded by platelet grains if the stress direction is perpendicular to the prismatic planes (Fig. 5(e)). It is clear that the way by which the fracture energy was absorbed is either through fracture of platelet grains or crack deflection along the basal planes aligned to the crack propagation direction. When direction of indentation stress is parallel to the prismatic planes, the breaking of platelet grains become impossible since shear stress is much easily deflected along these short base planes and continues the crack propagation along prismatic planes (Fig. 5(f)). In either case, the textured microstructure multiplies the route to absorb mechanical energy and will contribute to the improvement in fracture toughness.

Figure 6(a) shows a special set of plungers machined out to test the superplastic forming ability of NC-CNT/alumina ceramics [17]. A 1 wt\% NC$\mathrm{CNT} /$ alumina ceramic was pre-sintered in SPS furnace at temperature of $1200^{\circ} \mathrm{C}$ for $5 \mathrm{~min}$. Fully dense ceramic was then shifted into graphite die and was held

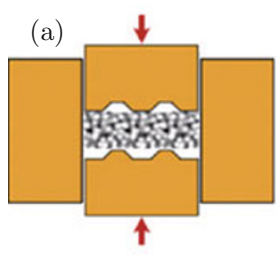

(b)
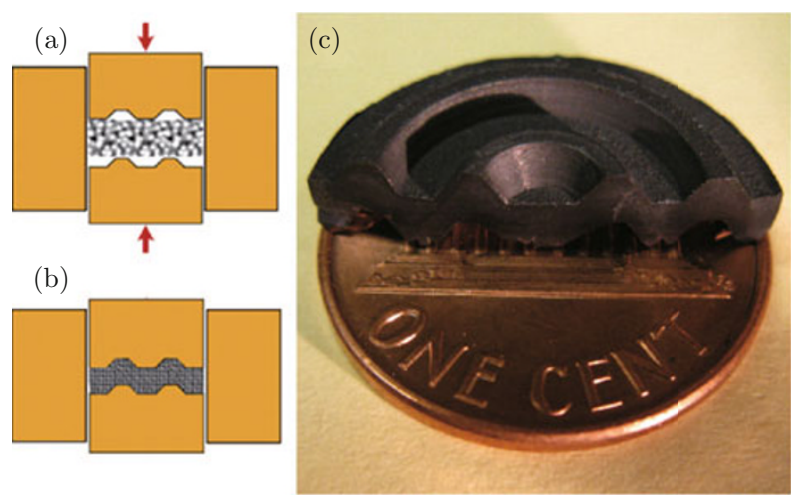

Fig. 6 (a) and (b) Superplastic forming process for making ceramic with complex shape. (c) A final shaped ceramic displayed on one cent. 
between patterned plungers (Fig. 6(b)). The superplastic forming operation was also performed in the SPS furnace and under the same condition as the in-situ compressive deformation test. A half of final shaped ceramic is displayed in Fig. 6(c). The smooth appearance of rim and surface of product demonstrates excellent ductility.

\section{Conclusions}

In conclusion, carbon nanotubes being chemically functionalized by non-covalent and covalent methods can mediate the high-temperature creep behavior of resultant CNT/alumina composites. The creepresistance property in the alumina composite filled by oxidized CNTs switch to excellent superplasticity when CNTs are replaced by non-covalent functionalized ones. An oxygen vacancy model is proposed and quantitatively analyzed by thermoluminescence technique. The microstructure of as-forged CNT/alumina ceramics demonstrates an anisotropic grain growth feature, which has an implication for improvement in fracture toughness.

\section{Acknowledgements}

This investigation was supported by grants from 'hundred Talents Programme' of The Chinese Academy of Sciences (KJCX2-EW-H06), Qianjiang excellent project (2011R10020) and Zhejiang NSF (Y4ll0376), National Natural Science Foundation of China (Grant No. 51172248), State Key Laboratory of Porous Metal Materials (PMM-SKL-1-2013) and NSF-CMMI (grant number CMMI-0700272). Q. Huang thanks Dr. Xinbo Yang for the help to collect the thermoluminescence data.

\section{References}

[1] J. W. Edington, K. N. Melton and C. P. Cutler, "Superplasticity", Prog. Mater. Sci. 21(2), 63-170 (1976). http://dx.doi.org/10.1016/ 0079-6425 (76) 90005-0

[2] I. A. Ovid'ko, "Nanodefects in nanostructures", Phil. Mag. Lett. 83(10), 611-20 (2003). http://dx.doi. org/10.1080/09500830310001593463

[3] F. Wakai, "Superplasticity of ceramics", Ceram. Int. 17(3), 153-63 (1991). http://dx.doi.org/10.1016/ 0272-8842(91) 90062-5

[4] F. Wakai, N. Kondo, H. Ogawa, T. Nagano and S. Tsurekawa, "Ceramics superplasticity: Deformation mechanisms and microstructures", Mater. Charact. 37(5), 331-41 (1996). http://dx.doi.org/10.1016/ S1044-5803 (96) 00174-X

[5] Amiya K. Mukherjee, "The rate controlling mechanism in superplasticity", Mate. Sci. Eng.
8(2), 83-89 (1971). http://dx.doi.org/10.1016/ 0025-5416 (71) 90085-1

[6] R. Raj, "Model for interface reaction control in superplastic deformation of non-stoichiometric ceramics", Mater. Sci. Eng. A Struct. Mater. 166(1-2), 89-95 (1993). http://dx.doi.org/10.1016/ 0921-5093 (93) 90313-4

[7] Q. Huang, Y. S. Bando, X. Xu, T. Nishimura, C. Y. Zhi, C. C. Tang, F. F. Xu, L. Gao and D. Golberg, "Enhancing superplasticity of engineering ceramics by introducing BN nanotubes", Nanotechnology, 18(48), 485706 (2007). http://dx.doi.org/10.1088/ 0957-4484/18/48/485706

[8] E. Zapata-Solvas, R. Poyato, D. Gomez-Garcia, A. Dominguez-Rodriguez, V. Radmilovic and N. P. Padture, "Creep-resistant composites of alumina and single-wall carbon nanotubes", Appl. Phys. Lett. 92(11), 11912 (2008). http://dx.doi.org/+10.1063/ 1.2899945

[9] A. Bataille, J. Crampon, and R. Duclos, "Upgrading superplastic deformation performance of finegrained alumina by graphite particles", Ceram. Int., 25(3), 215-222 (1999). http://dx.doi.org/10.1016/ S0272-8842(98) 00026-1

[10] P. Lu, Q. Huang, D. T. Jiang, B. Ding, Y. L. Hsieh, I. A. Ovid'ko and A. Mukherjee, "Highly dispersive carbon nanotube/alumina composites and their electrospun nanofibers", J. Am. Ceram. Soc. 92(11), 2583-2589 (2009). http://dx.doi.org/10. $1111 / j .1551-2916.2009 .03283 . x$

[11] G. D. Zhan, J. Kuntz, J. Wan, J. Garay and A. K. Mukherjee, "A novel processing route to develop a dense nanocrystalline alumina matrix $(<100$ $\mathrm{nm})$ nanocomposite material", J. Am. Ceram. Soc. 86(1), 200-202 (2003). http://dx.doi.org/10.1111/ j.1151-2916.2003.tb03306.x

[12] M. L. Toebes, T. A. Nijhuis, J. Hajek, J. H. Bitter, A. J. van Dillen, D. Y. Murzin and K. P. de Jong, "Support effects in hydrogenation of cinnamaldehyde over carbon nanofiber-supported platinum catalysts: Kinetic modeling", Chem. Eng. Sci. 60(21), 5682-5695 (2005). http://dx.doi.org/10. $1016 / \mathrm{j}$. ces . 2005.05.031

[13] Q. Huang, D. T. Jiang, I. A. Ovid'ko and A. Mukherjee, "High current induced damage on carbon nanotubes: case in spark plasma sintering", Script Mater. 63(12), 1181-1184 (2010). http://dx.doi.org/ 10.1016/j.scriptamat. 2010.08.030

[14] E. G. Yukihara and S. W. S. McKeever, "Optically stimulated luminescence (OSL) dosimetry in medicine", Phys. Med. Biol. 53(20), R351-R379 (2008). http://dx.doi.org/10.1088/0031-9155/53/20/R01

[15] L. A. Xue and I. W. Chen, "Superplastic alumina at temperatures below $1300^{\circ} \mathrm{C}$ using chargecompensating dopants", J. Am. Ceram. Soc. 79(1), 233-238 (1996). http://dx.doi.org/10.1111/j. 1151-2916.1996.tb07903.x

[16] X. B. Yang, H. J. Li, Q. Y. Bi, Y. Cheng, Q. Tang, X. B. Qian and J. Xu, "Growth of $\alpha-\mathrm{Al}_{2} \mathrm{O}_{3}: \mathrm{C}$ crystal with 
highly sensitive optically stimulated luminescence", J. Lumin. 129(5), 566-569 (2009). http://dx.doi.org/ $10.1016 / j \cdot j l u m i n .2008 .12 .015$

[17] D. T. Jiang, D. M. Hulbert, J. D. Kuntz, U. Anselmi-
Tamburini and A. K. Mukherjee, "Spark plasma sintering: A high strain rate low temperature forming tool for ceramics", Mater. Sci. Eng. A Struct. Mater. 463(1-2), 89-93 (2007). http://dx.doi.org/10.1016/ j.msea. 2006.07.163 